\title{
Heterozygosity and lungworm burden in harbour seals (Phoca vitulina)
}

\author{
JM Rijks ${ }^{1,2}$, JI Hoffman ${ }^{3}$, T Kuiken ${ }^{1}$, ADME Osterhaus ${ }^{1}$ and W Amos ${ }^{3}$ \\ ${ }^{1}$ Department of Virology, Erasmus Medical Center, Erasmus University Rotterdam, Rotterdam, The Netherlands; ${ }^{2}$ Dutch Wildlife Health \\ Center, Faculty of Veterinary Medicine, Utrecht University, Utrecht, The Netherlands and ${ }^{3}$ Department of Zoology, University of \\ Cambridge, Cambridge, UK
}

\begin{abstract}
In several studies, heterozygosity measured at around 10 microsatellite markers correlates with parasite load. Usually the effect size is small, but while this may reflect reality, it may also be possible that too few markers are used or the measure of fitness contains too much error to reveal what is actually a much stronger underlying effect. Here, we analysed over 200 stranded harbour seals (Phoca vitulina) for an association between lungworm burden and heterozygosity, conducting thorough necropsies on the seals and genotyping the samples obtained for 27 microsatellites. We found that homozygosity predicts higher worm burdens, but only in young animals, where the worms have the greatest
\end{abstract}

impact on fitness. Testing each locus separately, we found that a significant majority reveal a weak but similar trend for heterozygosity to be protective against high lungworm burden, suggesting a genome-wide effect, that is, inbreeding. This conclusion is supported by the fact that heterozygosity is correlated among markers in young animals but not in otherwise equivalent older ones. Taken as a whole, our results support the notion that homozygosity increases susceptibility to parasitic infection and suggest that parasites can be effective in removing inbred individuals from the population. Heredity (2008) 100, 587-593; doi:10.1038/hdy.2008.18; published online 9 April 2008

Keywords: heterozygosity-fitness correlation (HFC); harbour seal (Phoca vitulina); lungworm burden; Otostrongylus circumlitus; Parafilaroides gymnurus

\section{Introduction}

The publication of the measure mean d-squared, an estimator of microsatellite allele similarity, and the demonstration that it predicts aspects of fitness in deer and seals (Coltman et al., 1998; Coulson et al., 1998) stimulated renewed interest in the link between heterozygosity and fitness (David, 1998). Subsequent studies have developed both new and more effective measures for estimating heterozygosity (Coltman et al., 1999; Amos et al., 2001; Aparicio et al., 2006) and confirmed that panels of as few as 10 presumed neutral microsatellite markers often reveal statistically significant correlations with fitness. Over the last decade, the list of fitness traits found to be associated with heterozygosity has expanded greatly, from the initial analyses based on juvenile survival (Coltman et al., 1998), now to cover parasite susceptibility (Coltman et al., 1999), reproductive success (Slate et al., 2000; Hoffman et al., 2004) and even behavioural traits, such as territory size (Seddon et al., 2004). Such apparent ubiquity makes these heterozygosity-fitness correlations (HFCs) a potentially important component of natural selection and suggests that understanding their prevalence and basis could help elucidate a number of evolutionary processes.

Correspondence: Dr W Amos, Department of Zoology, University of Cambridge, Downing Street, Cambridge CB2 3EJ, UK.

E-mail:w.amos@cam.ac.uk

Received 10 October 2007; revised 1 February 2008; accepted 8 February 2008; published online 9 April 2008
Some of the strongest HFCs have been recorded in studies of parasite load (Coltman et al., 1999) and infectious disease. In rehabilitating sea lions, all classes of sick animals revealed elevated homozygosity (AcevedoWhitehouse et al., 2003), whereas in studies of infectious disease, heterozygosity has been implicated separately in both viral (Valsecchi et al., 2004) and bacterial (Acevedo-Whitehouse et al., 2003) diseases, as well as influencing the strength of the innate immune response (Hawley et al., 2005). However, the exact mechanism underlying these correlations remains obscure (Hansson and Westerberg, 2002; Pemberton, 2004). On the one hand, many authors have invoked inbreeding depression, arguing that heterozygosity at neutral markers reflects genome-wide heterozygosity, which in turn varies with inbreeding coefficient. On the other hand, both theory and simulations suggest that individuals with detectably non-zero inbreeding coefficients are usually too rare in nature to create HFCs, occurring only in small, isolated populations or species with strong polygyny (Balloux et al., 2004; Slate et al., 2004).

Here, we examine the relationship between heterozygosity and the macroscopic presence of lungworm infection in harbour seals (Phoca vitulina). Lungworm infection is an important cause of morbidity and mortality in harbour seals, in particular in young seals (Measures, 2001; Vercruysse et al., 2003; Lehnert et al., 2007a). Lungworm infection is caused by two macroparasites (Vercruysse et al., 2003), often found concurrently (Lehnert et al., 2007a): Otostrongylus circumlitus, a large species whose adults are easily visible in the 
principal airways and, Parafilaroides gymnurus, a smaller species found in the alveoli and smaller bronchioles. For the analysis, we used 27 polymorphic loci genotyped in a sample of 204 harbour seals that stranded along the Dutch coast, taking into account the relationship between lungworm burden and age. In addition, to test whether the relationship between heterozygosity and lungworm burden is dominated by a genome-wide rather than a single-locus effect, we first tested for a correlation in heterozygosity across loci and then compared the number of homozygotes and heterozygotes at every locus among seals in which worms were observed with those in which they were not seen.

\section{Materials and methods}

\section{The sample set}

The sample set was an exhaustive selection of tissue samples obtained from seals that stranded and died in the Dutch Wadden Sea in the period 1997-2003, whose death was associated either with lungworm infection $(n=26)$, phocine distemper virus infection (PDV; $n=169)$ or trauma or drowning in fishing nets $(n=9)$ and for which relevant data were available (Figure 1). The necropsies were performed following the procedure detailed in Kuiken and Baker (1991). This included the registration of available stranding data and clinical information, specifically: determination of species and sex, standard measurements, including nose-to-tail body length, and description of gross lesions. During gross necropsy, the bronchi and lung tissue were incised and examined visually for the presence of lungworms and associated lesions. Where necessary, samples for histology, virology, bacteriology, parasitology and toxicology were collected and tested to determine the probable cause of death. Death from lungworm infection or noninfectious causes of death was established based on gross lesions, presence of and numbers of parasites, nutritional state and stomach contents. Death from phocine distemper virus infection was established by gross lesions and confirmed by either reverse-transcriptase PCR or IgM serology (Jensen et al., 2002).

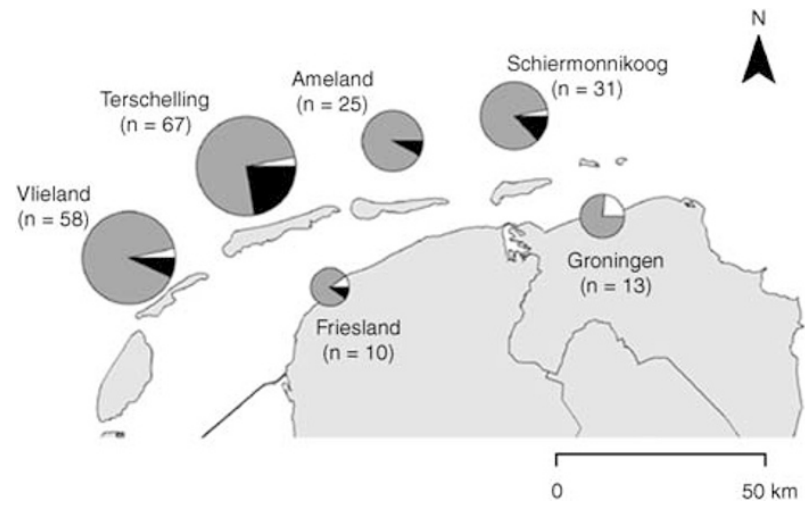

Figure 1 Spatial distribution and probable cause of death of the seals in the sample set. The diameter of the pie chart corresponds to the number of seals stranded at a particular location and the colours in the pie chart indicate the probable cause of death: death associated with lungworm infection (black), phocine distemper infection (grey) or trauma or by-catch (white).
The samples used for DNA extraction were mostly of kidney tissue, initially stored frozen at -20 and $-70{ }^{\circ} \mathrm{C}$, later transferred to $96 \%$ ethanol and stored at room temperature. In the absence of a kidney sample, lung, spleen or blood was used. A small number of kidney samples $(n=13)$ were stored in lysis buffer $(6 \mathrm{M}$ Guanidine-HCL, $10 \mathrm{~mm}$ Urea, $10 \mathrm{mM}$ Tris- $\mathrm{HCl}, 20 \%$ Triton-X100 (v/v), $\mathrm{pH} 4.4)$ at $-20^{\circ} \mathrm{C}$ and at room temperature. DNA was extracted using an adapted Chelex protocol (Walsh et al., 1991).

\section{Genotyping}

Microsatellite genotyping, scoring and data entry were conducted as described previously (Hoffman and Amos, 2005). Briefly, PCR reactions were carried out in $10-\mu 1$ reaction volumes containing $1 \mu \mathrm{l}$ template DNA, $1 \times$ Thermalase buffer (10 mM Tris- $\mathrm{HCl}(\mathrm{pH} 8.3), 50 \mathrm{mM} \mathrm{KCl}$, $1.5 \mathrm{mM} \mathrm{MgCl}_{2}, 0.1 \%$ Tween $20,0.1 \%$ gelatine, $0.1 \%$ IGEPAL), $60 \mathrm{mM}$ tetramethylammonium chloride (TMAC), $2.5 \%$ formamide, $0.1 \mathrm{mM}$ dGTP, $0.1 \mathrm{mM} \mathrm{dATP}$, $0.1 \mathrm{mM}$ dTTP, $0.02 \mathrm{mM}$ dCTP, 4 pmol of each primer, 0.25 units of Taq polymerase and $0.01 \mu \mathrm{Ci}\left[\alpha^{32} \mathrm{P}\right] \mathrm{dCTP}$. Loci were amplified using the following PCR profile: one cycle of $120 \mathrm{~s}$ at $94^{\circ} \mathrm{C}, 45 \mathrm{~s}$ at T1, $50 \mathrm{~s}$ at $72{ }^{\circ} \mathrm{C} ; 10$ cycles of $30 \mathrm{~s}$ at $94{ }^{\circ} \mathrm{C}, 45 \mathrm{~s}$ at $\mathrm{T} 1,50 \mathrm{~s}$ at $72{ }^{\circ} \mathrm{C} ; 25$ cycles of $30 \mathrm{~s}$ at $89^{\circ} \mathrm{C}, 45 \mathrm{~s}$ at $\mathrm{T} 2,50 \mathrm{~s}$ at $72{ }^{\circ} \mathrm{C}$; and one final cycle of $5 \mathrm{~min}$ at $72{ }^{\circ} \mathrm{C}$. For the majority of loci, T1 was $46^{\circ} \mathrm{C}$ and T2 was $48^{\circ} \mathrm{C}$. However, for Pv3, Hg6.1, OrrFCB7 and OrrFCB8, $\mathrm{T} 1$ and $\mathrm{T} 2$ were 50 and $55^{\circ} \mathrm{C}$ respectively. PCR products were resolved by electrophoresis on standard $6 \%$ polyacrylamide sequencing gels and detected using a phosphoimager (Fujifilm BAS-2500). Genotypes were scored by two independent observers (JMR and JIH) and entered manually into a Microsoft Excel spreadsheet. Genotypes were tested for deviations from HardyWeinberg equilibrium and linkage disequilibrium using GENEPOP (http://www.genepop.curtin.edu.au/, Raymond and Rousset, 1995). For each test, we set the dememorization number to 10000 , the number of batches to 1000 and the number of iterations per batch to 10000 .

\section{Calculation of heterozygosity}

Several alternative ways to calculate heterozygosity have recently been proposed, all of which aim to produce a measure that correlates most strongly with $F$, the inbreeding coefficient. These measures include methods to compensate for missing genotypes (standardized heterozygosity, SH, Coltman et al., 1999), to exploit the evolutionary similarity of different alleles (mean d-squared, Coulson et al., 1998) and to use allele frequencies to weight scores according to the alleles in the genotype (internal relatedness, IR, Amos et al., 2001) or the diversity of the loci being scored (HL, Aparicio et al., 2006). Which of these performs best depends on several factors, including the completeness of genotyping, the diversity of the loci being scored and the range of inbreeding coefficients, $F$, represented in the sample. However, mean d-squared is now seen as performing relatively poorly unless two genetically distinct populations have recently mixed (Balloux et al., 2004) whereas SH tends to perform marginally less well than IR across a range of scenarios (Amos et al., 2001; Balloux et al., 2004). Heterozygosity weighted by locus 
$\mathrm{HL}$ is a recently proposed method that has yet to be used widely, but simulations suggest that it can outperform IR, particularly at loci with higher allelic diversity (Aparicio et al., 2006). In view of the above, we chose to use both IR and HL to conduct a comparison.

\section{Data analyses}

Seals were categorized as 'infected' or 'uninfected' depending on the presence or absence of lungworms in the respiratory tract at gross necropsy. Using sex and body length to estimate age (McLaren, 1993), males up to $95 \mathrm{~cm}$ and females up to $90 \mathrm{~cm}$ were considered to be up to 1-year-old, and categorized as 'young' in this paper; the remaining seals referred to as 'older'.

The relationship between heterozygosity and lungworm burden was first analysed by comparing the mean of the measure of heterozygosity (HL, IR) of all infected seals $(n=54)$ to that of all uninfected seals $(n=150$; $t$-test). Then, as infection and mortality due to high worm burden is most likely to occur in the first year of life, we performed the same analysis for young seals (total $n=43$; 29 infected, 14 uninfected; $t$-test). To verify that the reduction to this age category was justified, we tested the significance of the interaction between age category (young, older) and lungworm burden (uninfected, infected) by performing a univariate analysis of variance on a model with the measure of heterozygosity (HL, IR) as dependent variable and age category (young, older) and lungworm status (uninfected, infected) as explanatory variables. These analyses were performed in SPSS.

Finally, any relationship between heterozygosity and lungworm burden could be due either to a genome-wide (inbreeding) effect or to a single locus effect caused by chance linkage between one or more of our markers and a gene experiencing balancing selection. To test which is the more likely mechanism in the current data set, we tested whether heterozygosity was correlated across loci using the method of Balloux et al. (2004). Here, the loci are divided randomly into two equal groups and then a correlation coefficient is calculated across individuals between the paired heterozygosity estimates, one from each group of markers. By repeating this process 100 times, each time dividing the markers into different groupings, one can assess the robustness of any correlation present. A robust positive correlation suggests that one or more inbred individuals are present in the group, with stronger correlations, suggesting greater numbers of inbred individuals and higher $F$-values. We applied this test to young animals $(n=43)$ and older animals $(n=161)$ separately. In addition, we used a Fisher's exact test to ask whether, at each locus in turn, there was a difference in heterozygosity between infected and uninfected young individuals. If one or a small number of loci contribute to any effect found, these should yield an equivalent number of significant tests. However, under a genome-wide effect, we expect to find that most loci reveal similar weak trends for heterozygotes to be uninfected.

\section{Results}

Microsatellite locus selection

We considered 94 published pinniped microsatellite primers (Allen, 1995; Allen et al., 1995; Coltman et al.,
1996; Gemmell et al., 1997; Goodman, 1997, 1998; Buchanan et al., 1998; Davis et al., 2002; HernandezVelaquez et al., 2005; Hayes et al., 2006; Hoffman et al., 2006; Wolf et al., 2006). Of these, 38 had previously been tested on four harbour seals from Scotland and were dismissed because they were either monomorphic or failed to amplify. The remaining 56 loci were tested on a panel of 43 Dutch harbour seals, revealing 30 that were polymorphic (Table 1), 19 that were monomorphic and 7 that either gave unscorable results or failed to amplify. Three of the thirty polymorphic loci (Lw18, Pvc74 and ZwcF09) were subsequently excluded because they were not in Hardy-Weinberg equilibrium. As previously reported by Davis et al. (2002), Lw18 is likely to be X chromosome-linked because Hardy-Weinberg equilibrium is observed in females (females, test for HWE $P=0.5444$ ) but not in males (males, test for HWE, $P=0.0000)$. This left 27 loci, all but one of which carried six or fewer alleles in the Dutch population, the last locus (Pv3) carrying 23 alleles (four alleles on average). Following sequential Bonferroni correction to compensate for multiple statistical tests, we found no evidence that any locus exhibited significant linkage disequilibrium with any other. Observed heterozygosity varied between 0.023 (M11a) and 0.905 (Pv3) and was on average 0.336 (see Table 1 ).

\section{Heterozygosity and lungworm burden}

In the sample as a whole ( $n=204$ individuals), mean measures of heterozygosity did not vary significantly between the uninfected and infected seals, though the difference in means did go in the direction expected if heterozygosity increases resistance to worm infection (mean $\mathrm{HL}_{150 \text { uninfected seals }}=0.512$; mean $\mathrm{HL}_{54 \text { infected seals }}=0.531$; t-test: $P=0.314$; mean $\mathrm{IR}_{150 \text { uninfected seals }}=0.014$; mean $\mathrm{IR}_{54 \text { infected seals }}=0.050$; $t$-test: $\left.P=0.313\right)$. However, lungworm burden was more common in young seals $(29 / 43$ infected) than in older seals (25/161 infected) and the proportion of deaths due to lungworm was also greater in young seals (Figure 2). When only the group of young seals was considered, the average heterozygosity was significantly greater in uninfected than in infected young seals, suggesting heterozygosity does increase resistance to lungworm infection (mean $\mathrm{HL}_{14}$ uninfected seals $=0.431$; mean $\mathrm{HL}_{29}$ infected seals $=0.543$; $t$-test: $P=0.006$; mean $\mathrm{IR}_{14 \text { uninfected seals }}=-0.114 ;$ mean $\mathrm{IR}_{29 \text { infected seals }}=0.061$; $t$-test: $P=0.027)$. The interaction between age category and lungworm burden was significant for HL but not for IR (HL univariate analysis of variance, $P=0.012$; IR univariate analysis of variance, $P=0.053$ ), validating the cutoff between age categories for $\mathrm{HL}$ but not quite for IR.

\section{Genome-wide or single locus effects}

When all adults were used to test for a correlation in heterozygosity among loci, the mean correlation coefficient was 0.018 ( \pm 0.06 s.d.) and did not differ significantly from zero, implying that this group contains few or no appreciably inbred individuals (Figure 3). In contrast, among young animals, the mean correlation coefficient was 0.213 ( \pm 0.087 s.d. $)$, much larger and significantly greater than zero, implying the presence of inbred individuals. In addition, when each locus in turn 
Table 1 Number of alleles, observed heterozygosity $\left(H_{\mathrm{O}}\right)$, expected heterozygosity $\left(H_{\mathrm{E}}\right)$ and probability values for derivation from Hardy-Weinberg equilibrium (HWE $P$-value) at 56 microsatellite loci for harbour seals that stranded along the Dutch coast

\begin{tabular}{|c|c|c|c|c|c|c|c|c|}
\hline Locus & $\begin{array}{l}\text { GenBank } \\
\text { accession No. }\end{array}$ & Isolated from species (reference) & $\begin{array}{l}\text { No. of alleles in } \\
\text { harbour seals in } \\
\text { previous } \\
\text { publications }\end{array}$ & $\begin{array}{l}\text { No. of alleles } \\
\text { in Scottish } \\
\text { harbour seals } \\
(\mathrm{n}=4)^{\mathrm{a}}\end{array}$ & $\begin{array}{l}\text { No. of alleles } \\
\text { in Dutch harbour } \\
\text { seals }(\mathrm{n}=231)\end{array}$ & $\mathrm{H}_{\mathrm{O}}$ & $\mathrm{H}_{\mathrm{E}}$ & $\begin{array}{l}\text { HWE } \\
\text { P-value }\end{array}$ \\
\hline \multicolumn{9}{|c|}{ The 27 polymorphic loci used in this study } \\
\hline Aa4 & - & $\begin{array}{l}\text { South American fur seal Arctocephalus australis } \\
\text { (Gemmell et al., 1997) }\end{array}$ & 2 (Gemmell et al., 1997) & 2 & 2 & 0.028 & 0.028 & 1.000 \\
\hline Hg6.1 & G02091 & Grey seal Halichoerus grypus (Allen et al., 1995) & $7^{\mathrm{b}}, 3^{\mathrm{c}}($ Goodman, 1998) & - & 3 & 0.249 & 0.271 & 0.031 \\
\hline Hg6.3 & G02092 & Grey seal H. grypus (Allen et al., 1995) & $8^{\mathrm{b}}, 4^{\mathrm{c}}($ Goodman, 1998$)$ & 3 & 3 & 0.383 & 0.421 & 0.297 \\
\hline Hg8.9 & G02094 & Grey seal H. grypus (Allen et al., 1995) & 2 (Gemmell et al., 1997) & - & 2 & 0.303 & 0.347 & 0.098 \\
\hline Hg8.10 & G02093 & Grey seal H. grypus (Allen et al., 1995) & 4 (Gemmell et al., 1997) & - & 2 & 0.489 & 0.500 & 0.789 \\
\hline Hgdii & G02095 & Grey seal H. grypus (Allen et al., 1995) & 2 (Gemmell et al., 1997) & 4 & 3 & 0.036 & 0.035 & 1.000 \\
\hline $\mathrm{H} 12$ & AF417692 & Leopard seal Hydrurga leptonyx (Davis et al., 2002) & 2 (Davis et al., 2002) & 1 & 2 & 0.419 & 0.437 & 0.535 \\
\hline Hl15 & AF140587 & Leopard seal H. leptonyx (Davis et al., 2002) & 2 (Davis et al., 2002) & 4 & 4 & 0.176 & 0.203 & 0.180 \\
\hline $\mathrm{Hl} 20$ & AF140589 & Leopard seal H. leptonyx (Davis et al., 2002) & 4 (Davis et al., 2002) & 4 & 3 & 0.224 & 0.210 & 0.834 \\
\hline Lw7 & AF140591 & Weddell seal Leptonychotes weddellii (Davis et al., 2002) & 4 (Davis et al., 2002) & 2 & 5 & 0.714 & 0.689 & 0.765 \\
\hline Lw20 & AF140595 & Weddell seal L. weddellii (Davis et al., 2002) & 4 (Davis et al., 2002) & 5 & 3 & 0.343 & 0.345 & 1.000 \\
\hline Lc28 & AF140584 & Crabeater seal Lobodon carcinophagus (Davis et al., 2002) & 3 (Davis et al., 2002) & & 4 & 0.096 & 0.102 & 0.432 \\
\hline M11a & - & $\begin{array}{l}\text { Southern elephant seal Mirounga leoni (Hoezel, unpublished } \\
\text { data as cited by (Gemmell et al., 1997)) }\end{array}$ & 2 (Gemmell et al., 1997) & 2 & 2 & 0.023 & 0.023 & 1.000 \\
\hline OrrFCB2 & G34934 & Walrus Odobenus rosmarus rosmarus (Buchanan et al., 1998) & - & 3 & 5 & 0.468 & 0.470 & 0.950 \\
\hline OrrFCB7 & G34928 & Walrus O. rosmarus rosmarus (Buchanan et al., 1998) & - & 3 & 3 & 0.482 & 0.504 & 0.747 \\
\hline OrrFCB8 & G34929 & Walrus O. rosmarus rosmarus (Buchanan et al., 1998) & - & 4 & 5 & 0.582 & 0.544 & 0.647 \\
\hline Pv2 & U65441 & Harbour seal Phoca vitulina vitulina (Goodman, 1997) & 3 (Goodman, 1997) & - & 3 & 0.309 & 0.349 & 0.136 \\
\hline Pv3 & U65442 & Harbour seal P. vitulina vitulina (Goodman, 1997) & $33^{\mathrm{b}}, 22^{\mathrm{c}}$ (Goodman, 1998) & - & 23 & 0.905 & 0.928 & 0.804 \\
\hline Pv9 & G02096 & Harbour seal P. vitulina (Goodman, 1997) & 1 (Goodman, 1997) & 2 & 2 & 0.046 & 0.063 & 0.015 \\
\hline Pv10 & U65443 & Harbour seal P. vitulina vitulina (Goodman, 1997) & $2^{\mathrm{b}}, 2^{\mathrm{c}}$ (Goodman, 1998) & & 2 & 0.058 & 0.056 & 1.000 \\
\hline Pv11 & U65444 & Harbour seal P. vitulina vitulina (Goodman, 1997) & $7^{b}, 3^{c}$ (Goodman, 1998) & 5 & 3 & 0.503 & 0.521 & 0.871 \\
\hline Pvc30 & L40986 & Harbour seal P. vitulina concolor (Coltman et al., 1996) & 2 (Coltman et al., 1996) & - & 4 & 0.521 & 0.483 & 0.483 \\
\hline 71HDZ301 & - & Steller sea lion Eumetopias jubatus (Huebinger et al., 2007) & - & 3 & 6 & 0.629 & 0.625 & 0.924 \\
\hline ZcwA12 & DQ836320 & $\begin{array}{l}\text { Galápagos sea lion Zalophus californianus wollebaeki } \\
\text { (Hoffman et al., 2006) }\end{array}$ & 3 (Hoffman et al., 2006) & 3 & 5 & 0.514 & 0.519 & 0.717 \\
\hline ZcwD02 & AM039816 & Galápagos sea lion Z. californianus wollebaeki (Wolf et al., 2006) & - & 3 & 2 & 0.126 & 0.155 & 0.027 \\
\hline ZcwF07 & DQ836326 & Galápagos sea lion Z. californianus wollebaeki (Hoffman et al., 2006) & 3 (Hoffman et al., 2006) & 3 & 3 & 0.261 & 0.240 & 0.112 \\
\hline ZcCgDh1.8 & AY 676475 & Californian sea lion Z. californianus (Hernandez-Velaquez et al., 2005) & - & 4 & 3 & 0.180 & 0.192 & 0.127 \\
\hline \multicolumn{9}{|c|}{ The three polymorphic loci not in Hardy-Weinberg equilibrium } \\
\hline Lw18 & AF140596 & Weddell seal Leptonychotes weddellii (Davis et al., 2002) & 4 (Davis et al., 2002) & 4 & 4 & 0.382 & 0.642 & 0.000 \\
\hline Pvc74 & L40988 & Harbour seal Phoca vituli concolor (Coltman et al., 1996) & 2 (Coltman et al., 1996) & - & 2 & 0.000 & 0.018 & 0.000 \\
\hline ZcwF09 & DQ836327 & $\begin{array}{l}\text { Galápagos sea lion Zalophus californianus wollebaeki } \\
\text { (Hoffman et al., 2006) }\end{array}$ & 3 (Hoffman et al., 2006) & 3 & 3 & 0.268 & 0.331 & 0.000 \\
\hline
\end{tabular}

-: not tested.

The allele frequencies are compared to allele frequencies found in other studies or populations.

${ }^{a}$ Hoffman et al., 2006 and Hoffman unpublished data.

${ }^{b}$ In harbour seals of the North Sea (Goodman, 1998).

In harbour seals of the Western Wadden Sea (Goodman, 1998). 


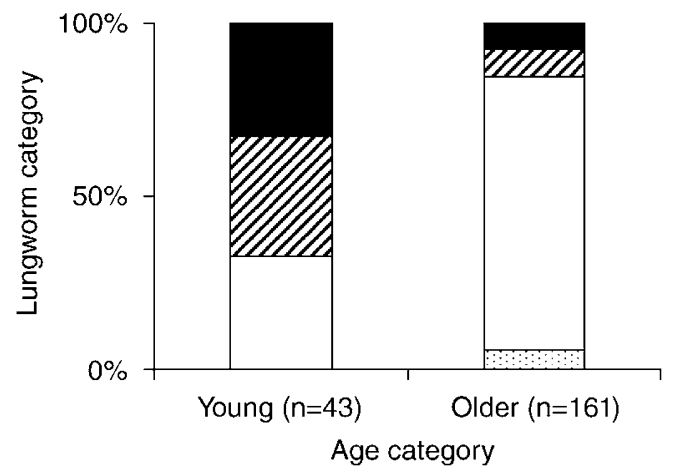

Figure 2 Relative frequency of lungworm infection in the two age groups (total $n=204$ ). Seals in which lungworms were observed macroscopically (infected) either died of lungworm infection (black areas) or phocine distemper virus infection (slanted hatched areas); seals in which no lungworms were observed macroscopically ('uninfected') died of phocine distemper virus infection (white areas) or by-catch or trauma (dotted area). Seals were classified into age groups based on sex and length. Males up to $95 \mathrm{~cm}$ and females up to $90 \mathrm{~cm}$ were classified as 'young', all larger seals as 'older'.

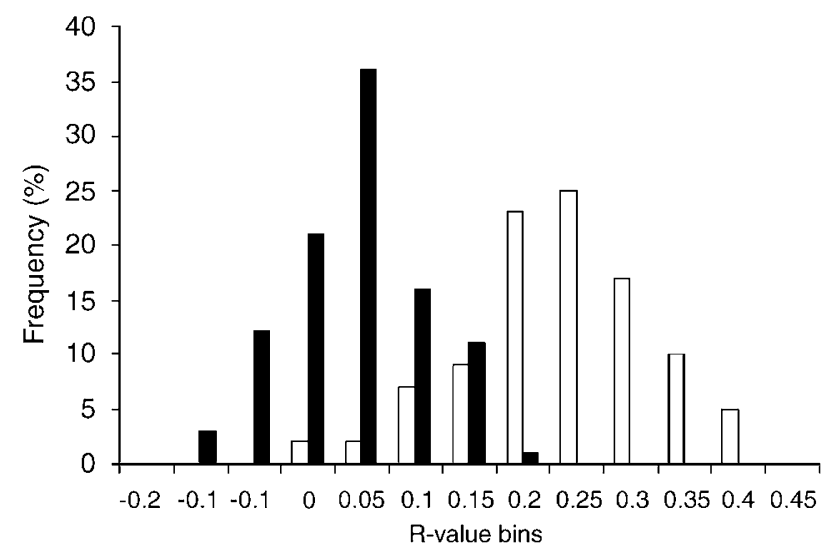

Figure 3 Correlation in heterozygosity among markers in older seals (black bars, $n=161$ ) compared with young seals (white bars, $n=43$ ). In each set of animals, the 27 microsatellite markers, for which the animals were typed, were divided randomly into two equal groups and the correlation coefficient, $R$, between the estimates for each group calculated. The bar chart above presents data for 100 replicates. Values centering on zero suggest that inbred individuals are rare or absent, while increasingly positive values suggest that the presence of inbred individuals (strictly, a higher variance in the underlying inbreeding coefficients of the sample).

was tested for a difference in heterozygosity between infected and uninfected young seals, none of the $P$-values were significant (Fisher's exact test at each locus). However, 20 of the 27 loci did reveal a tendency for greater homozygosity in the infected animals, a significant imbalance (Sign test, $P=0.019$ ). Such a pattern is most likely to result from a slight tendency towards heterozygote advantage affecting every locus, that is, a genome-wide or inbreeding effect, rather than one or a few loci showing a big effect.

\section{Discussion}

In this paper, we examined the relationship between heterozygosity and lungworm burden in harbour seals that stranded on the Dutch coast and died. Overall, there is no relationship between worm burden and heterozygosity. However, lungworms exert their maximum impact on fitness in young animals soon after weaning. When the analysis was repeated in this light, comparing affected young animals with all others, a significant difference in heterozygosity was found. The pattern appears to be driven by inbreeding depression, with young animals showing evidence of inbreeding not found among adults and no marker standing out as showing a dominant contribution.

Our finding of a link between heterozygosity and lungworm burden in young animals but not in the data set analysed as a whole appears to reflect the life history of the parasite. Lungworms appear to infect harbour seals early in life. The mode of infection is unknown, though it is likely that infective larvae develop in fish and infect seals through the oral route (Measures, 2001; Lehnert et al., 2007b). Some young seals develop higher burdens than others and, among these, some die as a result of their infections. Generally, in domestic animals, worm burden following primary infection depends on the exposure conditions, for example parasite intake, and on host immunity, first innate and then specific. The specific immunity that develops and helps clear the primary infection also impedes the development of worms in subsequent infections (Tizard, 2004), as has been shown, for example, in calves infected with lungworm (Dictyocaulus viviparus) (Eysker et al., 1994; Scott et al., 1996). The development of protective specific immunity against lungworms in harbour seals has not been proven, but seals do develop antibodies against lungworms (Elson-Riggins et al., 2004) and lungworms are uncommon in older seals. Our data reflect this in that the strongest association between genotype and worm burden occurs early in life when the impact of the worms is likely to be largest.

In revealing the lungworm HFCs, we compared two measures of heterozygosity: IR, which weights allele sharing by the frequencies of the alleles in a genotype, and HL, which weights heterozygosity by the variability of each locus at which an individual is homozygous. Our results largely support the claim made by Aparicio et al. (2006) that HL is often a 'better' measure in the sense that in most of the significant trends we find, HL generates a lower $P$-value than IR. We therefore endorse the use of HL as the measure of choice for studying heterozygosity-fitness correlations in natural populations, though it is still of interest to compare the two measures, since they are expected to perform somewhat differently depending on the variability of loci being used (Aparicio et al., 2006).

There is currently considerable debate concerning whether heterozygosity-fitness correlations are due mainly to genome-wide changes in heterozygosity brought about by inbreeding or through chance associations between markers and neighbouring genes under balancing selection (Hansson and Westerberg, 2002; Balloux et al., 2004; DeWoody and DeWoody, 2005; Ferreira and Amos, 2006). Despite our rather small sample size of affected young animals, our analysis suggests that the relationship between heterozygosity and lungworm burden is dominated by a genome-wide effect, that is, inbreeding. We provide two lines of evidence. First, heterozygosity is essentially uncorrelated across loci among adult animals, but is rather strongly correlated among young animals. Such a pattern is 
consistent with the young animals including some individuals with $F$-values that are high enough to detectably impact on the probability that any given marker is heterozygous. Just how many inbred individuals we have sampled cannot be determined without deploying hundreds rather than tens of markers. The second line of evidence is that, when each locus is tested separately for a relationship between heterozygosity and worm burden, no one locus stands out, but instead a significant majority reveal a trend in the direction of homozygosity conferring susceptibility. Such a pattern is consistent with a genome-wide effect.

The presence of a detectable genome-wide effect, and in particular, the large difference between adults and juveniles, is interesting in the context of how selection acts on a population through parasites and disease. It is known that harbour seals exhibit strong population substructure, with significant genetic differences between populations that are easily within the reach of dispersing youngsters (Goodman, 1998). Such structure has the potential to allow or even promote some level of inbreeding. In our sample of individuals from the Dutch population, we do indeed find evidence of inbred individuals, but only among the juveniles, not the much larger sample of adults. By implication, any individuals who are born to related parents are disproportionately likely to suffer lethal worm burdens, which in turn removes them from the population. This therefore agrees with earlier studies that suggested inbred individuals carry more parasites, a greater diversity of parasites and may provide a weak point through which new pathogens can enter the population (Coltman et al., 1999; Acevedo-Whitehouse et al., 2003; Valsecchi et al., 2004).

In conclusion, we reveal a signal in the direction of reduced heterozygosity correlating with lungworm burden in young seals. Our results emphasize the importance of accurately quantifying fitness. Worm burden alone reveals little unless considered alongside measures of age and an appreciation of the age-specific effects of lungworm infection on seal morbidity and mortality.

\section{Acknowledgements}

We thank the volunteers who cover the Dutch coast in search of stranded seals; the Seal Rehabilitation and Research Centre Lenie ' $t$ Hart for their interest in establishing the cause of death of seals that strand; Paulien Bunskoek, Fiona Read and Marco van de Bildt for assistance during sample selection; Hazel Nichols, Bill Lee and Dan Morrish for their help during the laboratory work; Kanchon Dasmahapatra for kindly providing logistical support; René Eijkemans for assistance with statistics; and the reviewers for their valuable comments.

\section{References}

Acevedo-Whitehouse K, Gulland F, Greig D, Amos W (2003). Disease susceptibility in California sea lions. Nature 422: 35.

Allen PJ (1995). Microsatellite Analysis of Grey seal (Halichoerus Grypus) Breeding Systems. PhD Thesis University of Cambridge: UK.

Allen PJ, Amos W, Pomeroy PP, Twiss SD (1995). Microsatellite variation in grey seals (Halichoerus grypus) shows evidence of genetic differentiation between two British breeding colonies. Mol Ecol 4: 653-662.

Amos W, Worthington Wilmer J, Fullard K, Burg TM, Croxall JP, Bloch D et al. (2001). The influence of parental relatedness on reproductive success. Proc R Soc Lond Biol Sci 268: 2021-2027.

Aparicio JM, Ortego J, Cordero PJ (2006). What should we weigh to estimate heterozygosity, alleles or loci? Mol Ecol 15: 4659-4665.

Balloux F, Amos W, Coulson T (2004). Does heterozygosity estimate inbreeding in real populations? Mol Ecol 13: 3021-3031.

Buchanan FC, Maiers LD, Thue TD, De March BGE, Stewart REA (1998). Microsatellites from the Atlantic walrus Odobenus rosmarus rosmarus. Mol Ecol 7: 1083-1090.

Coltman DW, Bowen WD, Wright JM (1996). PCR primers for harbour seal (Phoca vitulina concolour) microsatellites amplify polymorphic loci in other pinniped species. Mol Ecol 5: $161-163$

Coltman DW, Don Bowen W, Wright JM (1998). Birth weight and neonatal survival of harbour seal pups are positively correlated with genetic variation measured by microsatellites. Proc R Soc Lond Biol Sci 265: 803-809.

Coltman DW, Pilkington JG, Smith JA, Pemberton JM (1999). Parasite-mediated selection against inbred Soay sheep in a free-living, island population. Evolution 53: 1259-1267.

Coulson TN, Pemberton JM, Albon SD, Beaumont M, Marshall TC, Slate J et al. (1998). Microsatellites reveal heterosis in red deer. Proc R Soc Lond Biol Sci 265: 489-495.

David P (1998). Heterozygosity-fitness correlations: new perspectives on old problems. Heredity 80: 531-537.

Davis CS, Gelatt S, Siniff D, Strobeck C (2002). Dinucleotide microsatellite markers from the Antarctic seals and their use in other pinnipeds. Mol Ecol 2: 203-208.

DeWoody YD, DeWoody JA (2005). On the estimation of genome-wide heterozygosity using molecular markers. J Hered 96: 85-88.

Elson-Riggins JG, Riggins SA, Gulland FMD, Platzer EG (2004). Immunoglobulin responses of northern elephant and Pacific harbour seals naturally infected with Otostrongylus circumlitus. J Wildlife Dis 40: 466-475.

Eysker M, Boersma JH, Cornelissen JB, Kooyman FNJ, De Leeuw WA, Saatkamp HW (1994). An experimental field study on the build up of lungworm infections in cattle. Vet $Q$ 16: 144-147.

Ferreira AGA, Amos W (2006). Inbreeding depression and multiple regions showing heterozygote advantage in Drosophila melanogaster exposed to stress. Mol Ecol 15: 3885-3893.

Gemmell NJ, Allen PJ, Goodman SJ, Reed JZ (1997). Interspecific microsatellite markers for the study of pinniped populations. Mol Ecol 6: 661-666.

Goodman SJ (1997). Dinucleotide repeat polymorphisms at seven anonymous microsatellite loci cloned from the European harbour seal (Phoca vitulina vitulina). Anim Genet 28: 308-322.

Goodman SJ (1998). Patterns of extensive genetic differentiation and variation among European harbour seals (Phoca vitulina vitulina) revealed using microsatellite DNA polymorphisms. Mol Biol Evol 15: 104-118.

Hansson B, Westerberg L (2002). On the correlation of heterozygosity and fitness in natural populations. Mol Ecol 11: 2467-2474.

Hawley DM, Sydenstricker KV, Kollias GV, Dhondt AA (2005). Genetic diversity predicts pathogen resistance and cellmediated immunocompetence in house finches. Biol Lett $\mathbf{1}$ : 326-329.

Hayes SA, Pearse DE, Costa DP, Harvey JT, Le Boeuf BJ, Garza JC (2006). Mating system and reproductive success in eastern Pacific harbour seals. Mol Ecol 15: 3023-3034.

Hernandez-Velaquez FD, Galindo-Sanchez CE, Taylor MI, De la Rosa-Velez J, Cote IM, Schramm Y et al. (2005). New 
polymorphic microsatellite markers for California sea lions (Zalophus californianus). Mol Ecol Notes 5: 140-142.

Hoffman JI, Amos W (2005). Microsatellite genotyping errors: detection approaches, common sources and consequences for paternal exclusion. Mol Ecol 14: 599-612.

Hoffman JI, Boyd IL, Amos W (2004). Exploring the relationship between parental relatedness and male reproductive success in the Antarctic fur seal Arctocephalus gazella. Evolution 58: 2087-2099.

Hoffman JI, Steinfartz S, Wolf JBW (2006). Ten novel dinucleotide microsatellite loci cloned from the Galapagos sea lion (Zalophus californianus wollebaeki) are polymorphic in other pinniped species. Mol Ecol Notes 7: 103-105.

Huebinger RM, Louis EE, Gelatt T, Rea LD, Bickham JW (2007). Characterization of eight microsatellite loci in Steller sea lions (Eumetopias jubatus). Mol Ecol Notes 7: 1097-1099.

Jensen T, Van de Bildt MWG, Dietz HH, Andersen TH, Hammer AS, Kuiken T et al. (2002). Another phocine distemper outbreak. Science 297: 209.

Kuiken T, Baker JR (1991). Guidelines for the Postmortem and Tissue Sampling of Seals. Zoological Society of London: London. pp 1-16.

Lehnert K, Raga JA, Siebert U (2007a). Parasites in harbour seals (Phoca vitulina) from the German Wadden Sea between two Phocine Distemper Virus epidemics. Helgol Mar Res 61: 239-245.

Lehnert K, Samson-Himmelstjerna G, Fonfara S, Walter T, Siebert U (2007b). Life cycle of lungworms in porpoises and seals: molecular tools determine vertebrate intermediate hosts. Abstract 21st conference of the European Cetacean Society, 22-25 April 2007, Donostia-San Sebastian: Spain. pp 14-15 (http://www.azti.es/ecs2007/documents/ abstracts.pdf)

McLaren IA (1993). Growth in pinnipeds. Biol Rev 68: 1-79.

Measures LN (2001). Lungworms of Marine Mammals. In: Samuel WM, Pybus MJ, Kocan AA (eds). Parasitic Diseases of Wild Mammals. Iowa State University Press/Ames, pp 279-300.
Pemberton JM (2004). Measuring inbreeding depression in the wild: the old ways are the best. Trends Ecol Evol 19: 613-615.

Raymond M, Rousset F (1995). GENEPOP (version 1.2): population genetics software for exact tests of ecumenicism J Hered 86: 248-249.

Scott CA, McKeand JB, Devaney E (1996). A longitudinal study of local and peripheral isotype/subclass antibodies in Dictyocaulus viviparus-infected calves. Vet Immunol Immunopathol 53: 235-247.

Seddon N, Amos W, Mulder RA, Tobias JA (2004). Male heterozygosity predicts territory size, song structure and reproductive success in a cooperatively breeding bird. Proc $R$ Soc Lond Biol Sci 271: 1823-1829.

Slate J, David P, Dodds KG, Veenvliet BA, Glass BC, Broad TE et al. (2004). Understanding the relationship between the inbreeding coefficient and multilocus heterozygosity: theoretical expectations and empirical data. Heredity 93: 255-265.

Slate J, Kruuk LEB, Marshall TC, Pemberton JM, Clutton-Brock TH (2000). Inbreeding depression influences lifetime breeding success in a wild population of red deer (Cervus elaphus). Proc R Soc Lond Biol Sci 267: 1657-1662.

Tizard IR (2004). Veterinary Immunology, an Introduction, 7 edn. Saunders: Philadelphia.

Valsecchi E, Amos W, Raga JA, Podesta M, Sherwin W (2004). The effects of inbreeding on mortality during a morbillivirus outbreak in the Mediterranean striped dolphin (Stenella coeruleoalba). Anim Conserv 7: 139-146.

Vercruysse J, Salomez A, Ulloa A, Alvinerie M, Osterhaus A, Kuiken T (2003). Efficacy of ivermectin and moxidectin against Otostrongylus circulitus and Parafilaroides gymnurus in harbour seals (Phoca vitulina). Vet Record 152: 130-134.

Walsh PS, Metzger DA, Higuchi R (1991). Chelex100 as a medium for simple extraction of DNA for PCR-based typing from forensic material. Biotechniques 10: 506-513.

Wolf JBW, Tautz D, Caccone A, Steinfartz S (2006). Development of new microsatellite loci and evaluation of loci from other pinniped species for the Galapagos sea lion (Zalophus californiansus wollebaeki). Conserv Genet 7: 461-465. 